\title{
Plant Production in Controlled Environments
}

\author{
Genhua Niu ${ }^{1, *(D)}$ and Joseph Masabni ${ }^{2}$ \\ 1 Texas A\&M AgriLife Research, Texas A\&M University, 1380 A\&M Circle, El Paso, TX 79927, USA \\ 2 Texas A\&M AgriLife Extension, Texas A\&M University, 1710 FM 3053 N, Overton, TX 75684, USA; \\ jmasabni@ag.tamu.edu \\ * Correspondence: gniu@ag.tamu.edu; Tel.: +1-915-859-9111
}

Received: 17 September 2018; Accepted: 19 September 2018; Published: 21 September 2018

\begin{abstract}
Crop production in open fields is increasingly limited by weather extremes and water shortages, in addition to pests and soil-borne diseases. In order to increase crop yield, quality, and productivity, controlled environment agriculture (CEA) can play an important role as an alternative and supplemental production system to conventional open field production. CEA is any agricultural technology that enables growers to manipulate the growing environment for improved yield and quality. CEA production systems include high tunnels, greenhouses, and indoor vertical farming, as well as hydroponics and aquaponics. Currently, 'low-tech' CEA techniques such as high tunnels (plastic greenhouses with minimum or no cooling and heating) are primarily utilized in developing countries where labor costs are relatively low, and China has by far the largest area covered by high tunnels or 'Chinese-style' solar greenhouses. The most control-intensive 'high-tech' CEA approach, namely indoor vertical farming, has gained tremendous attention in the past decade by researchers and entrepreneurs around the world, owing to advancements in lighting technology, including use of light emitting diodes (LEDs), and increasing urbanization with new market opportunities. This special issue covers some of the CEA topics such as LED lighting, substrate, and hydroponics.
\end{abstract}

Keywords: controlled environment agriculture (CEA); indoor vertical farming; LED; hydroponics; plant factory

\section{Introduction}

Traditionally, crops are produced in soil-based open field systems. Due to seasonality, environmental extremes, and soil-borne diseases, crop yield and quality varies significantly, and yearround production is impossible in most regions for most crops. Controlled environment agriculture (CEA) is a technology for plant production in environmentally-controlled structures such as high tunnels, greenhouses, growth chambers, or indoor vertical farming (warehouse farming). The aim of CEA is to provide protection from pests and diseases and maintain growing conditions for optimizing plant growth and quality. The environmental conditions inside greenhouses and high tunnels are still dependent on outside conditions such as temperature and solar radiation, while those inside an indoor CEA can be controlled precisely at desirable levels because artificial lighting is used instead of sunlight. With the advancement of LED technologies, customized light spectra have been made possible. Thus, manipulating light quality (or the spectrum) and light intensity to enhance plant growth and quality has become one of the most popular research fields in recent years, and this special issue has three articles on this subject [1-3].

\section{Manipulating Light in Indoor Vertical Farming}

For indoor vertical farming, electrical costs for lighting are the highest among all operational costs [4]. Therefore, many researchers have devoted efforts to developing innovative and cost-effective 
lighting strategies. Light is one of the most important environmental factors influencing plant growth and development. Plant growth increases with light intensity; however, plants use light less efficiently as the intensity increases [5]. For indoor vertical farming, it is imperative to determine the lowest possible light intensity or daily light integral (DLI), with corresponding lowest electricity costs, but with little compromise on yield and quality [5]. Researchers have attempted to manipulate light intensity, photoperiod, light spectrum, lighting direction (downward, sideways, or intra-canopy), and lighting with specific wavelengths delivered at specific timings [6-9]. In addition, others have tried different combinations of varying wavelengths of LEDs, which can be turned on simultaneously, alternating or with partial overlap of different LEDs [10]. The goal has been to use less electrical energy to achieve the same yield and quality. In this special issue, Chinchilla et al. [2] evaluated growth and physiological responses of two lettuce cultivars exposed to small changes in light quality and intensity within a 24-h period. They found that $1 \mathrm{~h}$ of low intensity end-of-day blue light has the potential to promote lettuce growth by increasing leaf area and shoot fresh mass when the main DLI from sole-source lighting is provided by broadband white LEDs.

Production of desirable secondary compounds, which affect color, flavor, and aroma, is also strongly dependent on both light intensity and quality [1]. The amounts of total anthocyanin, phenolics, and flavonoids in sweet basil were positively correlated to DLIs [5]. Plant morphology (height, branching, internode length, etc.) was influenced by both light quality and intensity. Therefore, management of lighting in indoor vertical farming system can be a powerful tool.

\section{Other Environmental Factors in CEA}

Regardless of CEA type, there are five essential environmental conditions that affect plant growth and development: temperature, light, $\mathrm{CO}_{2}$, water, and nutrients. A significant number of studies were carried out more than two decades ago on controlling greenhouse temperatures for floricultural crop production. Supplemental lighting when natural light is low in winter months and low-light intensity photoperiodic lighting for flowering control have been common approaches. In this issue, the effect of elevated temperature and potassium $(\mathrm{K})$ on biomass and quality of lettuce was investigated and results suggested that temperature is a stronger regulatory factor than increasing $\mathrm{K}$ in the determination of lettuce yield and quality [11].

In CEA, soilless substrates or hydroponics (water culture) have been used instead of soil. Solid substrates not only serve as a support of roots, but also affect water and nutrient use efficiency. In addition, some substrates are chemically inactive or inert, while others contain chemically active ingredients. Nevertheless, the 'best' substrate is often crop dependent. The availability and cost of ingredients of the substrates also play an important role in deciding if the substrate is suitable for commercial production. Arce and Rivera [12] evaluated different substrate mixes and quantities of fertilizers on the growth of citrus rootstocks. The results showed that different rootstocks responded differently, but rice husk substrate was not suitable for citrus tree production at the nursery level.

Biochar is a byproduct of thermochemical pyrolysis for bioenergy production and is considered a possible amendment to soilless substrates or soil in field. Peat moss is one of the most common ingredients in substrates for greenhouse production. However, most peat moss is harvested in Canada. Seeking a sustainable, locally available alternative for peat moss is vital. Guo et al. [13] conducted a greenhouse study to evaluate the growth and development of poinsettia grown in a commercial peat-based substrate amended with biochar at different ratios along with different fertigation regimes [13]. They concluded that up to $80 \%$ biochar could be used as an amendment to peat-based substrate with acceptable growth and no change in quality.

Growing crops in a hydroponic system under a controlled environment has gained interest among growers and entrepreneurs worldwide in recent years, especially for food crops such as leafy greens and herbs. Nutrient solutions in a hydroponic system are often recirculated, and thus high-quality water is often used. However, the availability of high-quality water is often limited. There is a need to evaluate the impact of water quality on nutrient solution management and on plant growth and 
quality. Niu et al. [14] conducted two greenhouse experiments to examine the growth and mineral nutrition of four leafy vegetables in a nutrient film technique system with water of low to moderate salinity [14]. They found that the tested vegetables differed in response to various types of water used as a supplement or as source water. They also noted that N, P, and K depleted more rapidly than other macronutrients, and that nutrient solution replacement in the reservoir was needed only when the unwanted ion (e.g., sodium and chloride) concentrations reached harmful levels, which are crop dependent.

\section{Conclusions}

An increasing population, urbanization, and climate change have contributed to decreasing global stocks of water and arable land per capita. Under these circumstances, more 'sustainable' crop production systems are needed. In other words, more food needs to be produced with less arable land and less water. Innovative CEA is an essential future agricultural model, and the papers in this SI have addressed some of the key topics pertinent to advancing CEA. Current advanced CEA production systems (well-controlled greenhouses and indoor vertical farming) face challenges of high initial investment and high operational costs. We envision future CEA will employ more advanced technologies such as automation, nanotechnologies, and artificial intelligence to increase crop productivity and optimize cost efficiency.

Author Contributions: G.N. drafted and J.M. revised. Both authors improved and finalized the article.

Acknowledgments: The authors would like to thank all authors contributing to this special issue. Special thanks goes to the journal Editor-in-Chief of Horticulturae and the Assistants for providing substantial support in handling the manuscripts and reviews.

Conflicts of Interest: The authors declare no conflict of interest.

\section{References}

1. Dou, H.; Niu, G.; Gu, M.; Masabni, J.G. Effects of light quality on growth and phytonutrient accumulation of herbs under controlled environment. Horticulturae 2017, 3, 36. [CrossRef]

2. Chinchilla, S.; Izzo, L.G.; van Santen, E.; Gomez, C. Growth and physiological responses of lettuce grown under pre-down or end-of-day sole source light-quality treatments. Horticulturae 2018, 4, 8. [CrossRef]

3. Clavijo-Herrera, J.; van Santen, E.; Gomez, C. Growth, water-use efficiency, stomatal conductance, and nitrogen uptake of two lettuce cultivars grown under different percentages of blue and red light. Horticulturae 2018, 4, 16. [CrossRef]

4. Kozai, T.; Niu, G.; Takagaki, M. Plant Factory: An Indoor Vertical Farming System for Efficient Quality Food Production; Academic Press: San Diego, CA, USA, 2015.

5. Dou, H.; Niu, G.; Gu, M.; Masabni, J.G. Responses of sweet basil to different DLIs in photosynthesis, morphology, yield, and nutritional quality. HortScience 2018, 53, 496-503. [CrossRef]

6. Bugbee, B. Toward an Optimal Spectral Quality for Plant Growth and Development: The Importance of Radiation Capture. In Proceedings of the VIII International Symposium on Light in Horticulture, East Lansing, MI, USA, 22-26 May 2016; pp. 1-12.

7. Joshi, J.; Zhang, G.; Shen, S.; Supaibulwatana, K.; Watanabe, C.K.A.; Yamori, W. A combination of downward lighting and supplemental upward lighting improves plant growth in a closed plant factory with artificial lighting. HortScience 2017, 52, 831-835. [CrossRef]

8. Kuno, Y.; Shimizu, H.; Nakashima, H.; Miyasaka, J.; Ohdoi, K. Effects of irradiation patterns and light, quality of red and blue light-emitting diodes on growth of leaf lettuce (Lactuca sativa L. 'Greenwave'). Environ. Control Biol. 2017, 55, 129-135. [CrossRef]

9. Zhang, G.; Shen, S.; Takagaki, M.; Kozai, T.; Yamori, W. Supplemental upward lighting from underneath to obtain higher marketable lettuce (Lactuca sativa) leaf fresh weight by retarding senescence of outer leaves. Front. Plant Sci. 2015, 6, 1110. [CrossRef] [PubMed] 
10. Chen, X.L.; Yang, Q.C.; Song, W.P.; Wang, L.C.; Guo, W.Z.; Xue, X.Z. Growth and nutritional properties of lettuce affected by different alternating intervals of red and blue LED irradiation. Sci. Hortic. 2017, 223, 44-52. [CrossRef]

11. Sublett, W.L.; Barickman, T.C.; Sams, C.E. Effects of elevated temperature and potassium on biomass and quality of dark red 'Lollo Rosso' lettuce. Horticulturae 2018, 4, 11. [CrossRef]

12. Arce, S.C.; Rivera, D. New media components and fertilization to accelerate the growth of citrus rootstocks grown in a greenhouse. Horticulturae 2018, 4, 10. [CrossRef]

13. Guo, Y.; Niu, G.; Starman, T.; Volder, A.; Gu, M. Poinsettia growth and development response to container root substrate with biochar. Horticulturae 2018, 4, 1. [CrossRef]

14. Niu, G.; Sun, Y.; Masabni, J.G. Impact of low and moderate salinity water on plant performance of leafy vegetables in a recirculating NFT system. Horticulturae 2018, 4, 6. [CrossRef]

C 2018 by the authors. Licensee MDPI, Basel, Switzerland. This article is an open access article distributed under the terms and conditions of the Creative Commons Attribution (CC BY) license (http://creativecommons.org/licenses/by/4.0/). 